\title{
Pre-admission Encounter
}

National Cancer Institute

\section{Source}

National Cancer Institute. Pre-admission Encounter. NCI Thesaurus. Code C150757.

A patient encounter that takes place before the planned date for a medical service. 